\title{
Submission Anxiety: ORCID, Publons, Cabell's, APC, Index Factor, Open Access, "Predatory" and Wait Time (As Well as Other Things)
}

\author{
Michael F. Shaughnessy*
}

Department of Special Education, Eastern New Mexico University, New Mexico, USA

*Corresponding author: Shaughnessy MF, Department of Special Education, Eastern New Mexico University, New Mexico, USA, Tel: 575-562-2791; E-mail: michael.shaughnessy@enmu.edu

Received: January 17, 2021; Accepted: January 26, 2021; Published: February 02, 2021

In this day and age, there is increased pressure for scholars and researchers to publish the results of their medical, psychological, educational and other research. This paper explores some of the anxiety provoking issues that confront scholars and researchers in the current zeitgeist.

While the internet and world wide web has increased our ability to procure information, knowledge and data from all over the world, it has also resulted in a good deal of dismay, depression, stress and anxiety regarding the publication process. This paper will review some of the many concerns that confront scholars in today's world and discusses some legitimate concerns.

In past years, it was relatively simple to submit a paper for publication. One put a piece of paper in a typewriter, typed up the literature review, the method, the results and relevant statistics- and mailed it off to some office somewhere- where apparently an Editor reviewed it-perhaps before or after sending it out for Peer Review- and then a few weeks or months later, a letter would arrive indicating acceptance or rejection.

Currently, due to many factors, the process has become more complex and intricate. Currently an author/researcher has to download their paper into some platform- follow a number of intricate complex steps, include a plethora of information (one's ORCID---if they have an ORCID number) and various contact venues- such as a phone or fax or e-mail or SKYPE or WhatsApp or all of the above!

This is a very time-consuming process-particularly if one is not familiar with the 7,8,9 or even 10 steps involved in the processsince some "platforms" want to know if the author has a particular reviewer in mind, or if the author does not want their former chair to review the paper.

Citation: Shaughnessy MF. Submission Anxiety: ORCID, Publons, Cabell's, APC, Index Factor, Open Access, "Predatory" and Wait Time (As Well as Other Things). J Anxiety Depress. 2021;4(1):132. 
www.yumedtext.com | February-2021 | ISSN: 2582-3264 | https://dx.doi.org/10.46527/2582-3264.132

Then this vast amount of information is sent off somewhere- and then perhaps it is reviewed by someone in some foreign country who may indicate that one of the 7 or 8 steps was not followed. Or even worse---if the word limit was exceeded! Some journals mandate a 10,000-word limit- and woe to those scholars who may have a paper at 10,005 words- since they will receive a "nasty gram" indicating that their work does not meet the criteria of that journal.

On occasion, a new Ph.D. will be asked for their ORCID. When confronted with this- the brand-new Ph.D. may have no clue or insight as to what this all means- and wonder the meaning behind it all. If the journal platform requires this ORCID- then the process is slowed down until the researcher can figure out, how much this will cost and if their university has to pay for it.

Then there is some required information perhaps about PUBLONS- which has no connection to any pub in Great Britain. Upon closer examination it appears that Publons is trying to recognize those peer reviewers who may spend 5 minutes, or 5 hours reviewing a paper where the author used nonparametric statistics, when they should have used simple parametric statistics. Or they spend 5 hours reviewing a 50-page paper with a sample size of 5 (discerned only at the end of the paper).

Before a lot of the above occurs, some scholars have to make sure that the journal that they are submitting to - has been approved by someone named Cabells or some organization names Cabells that apparently has a whitelist and a (gasp!) blacklist. (The blacklist seems to indicate that the journal has not been in existence for a long time- or that perhaps there is a page charge or publication fee of about 1000 American Dollars- (a much larger sum in Great Britain pounds since they are no longer on the Euro (perhaps they never were).

And sometimes prior to this entire process- the submitter is informed that there will be an APC- Article Processing Charge but there is no guarantee that the paper will eventually be published. Apparently, one or two reviewers have to be paid perhaps to read the paper and make some comments about the paper.

The researcher, having submitted the paper now may have second thoughts- they peruse the journal to find that it has an impact factor of 1.9 (similar to my GPA in my first semester of college) At this point, there is some concern as to whether or not the scholar has made a Big mistake- but now, having submitted the paper, he or she must wait what appears to be eons to hear back from the Editor or Secretary or " Editorial Team" (Often one gets correspondence from an "Editorial Team" which may consist of the Editor, the Co-Editor and the Secretary who brings Earl Gray tea on occasion).

Upon further examination- the scholar finds that the journal is an " Open Access " journal. Beginning scholars may have no real clue as to what this means, and even more seasoned researchers may ponder the true meaning of being published in an "Open Access" journal.

The scholar meanders around the Internet after being rejected by a peer reviewed journal or a refereed journal only to encounter what some may describe as a "Predatory Journal".

Jeffrey Beall many years ago began to describe these "predatory journals" who may simply be seeking to make money - from eager fledgling scientists who need to submit their research to some administrative university body. 
www.yumedtext.com | February-2021 | ISSN: 2582-3264 | https://dx.doi.org/10.46527/2582-3264.132

Once a scholar submits a paper, they are often confronted with " wait time" (depending on what time of year they submit- this could be anywhere from 2 months to 12 months- even longer for some journals that receive a massive number of submissions and who do not have a small army of reviewers. Wait time is perplexing since the scholar is in a state of limbo. The more adventurous scholars present their work at some conference and thus have a nice vacation to some foreign land to present their work before a number of other somewhat bored scholars with tepid, vapid, research that may be appropriately insipid.

Confronted with all of the above- there are the usual setbacks and concerns from the Editor who bemoans the " small sample size " or who indicates the first two reviewers had very positive comments- but the third wanted a series of clarifying experiments. Those knowledgeable of the process recognize the difficulties presented by the third reviewer and one wonders where the third reviewer went to school and if that third reviewer recognized the author of the paper has had a vindictive nature.

All of these concerns have been cursorily addressed by this author (Shaughnessy and Teixeira [1] and many other scholarsmost notably Beall [2,3,4], Teixeira da Silva JA, Tsigaris P [5]).

Publication "ethics" are also of concern since peer reviewers do not always agree, peer reviewers do not always agree with the Editor and the Editor does not always agree with the reviewers. Add to this dilemma is the fact that reviewers are also dealing with their own problems (death, divorce, drugs, and alcoholism) and difficulties.

Other Concerns: Some journals are indexed in EBSCO, Ulrich's, DRJI (whatever that is) InfoBase Index and Gale. Not all people know what these are- and while it may be incumbent upon scholars to find out- it would also be helpful for journals to specify what exactly these things are- while librarians may know the meaning of DRJI, not all researchers do.

More Other Concerns: One journal must be really good because they indicate that they are in CrossRef, CrossCheck, Cabell's, Ulrich's, Griffith Research Online, Google Scholar, Education.edu, Informatics, Universe Digital Library, Standard Periodical Directory, Gale, Open J-Gate, EBSCO, Journal Seek, DRJI (I still don't know what that stands for,) ProQuest, BASE, InfoBase Index, OCLC, IBSS, Academic Journal Databases and Scientific Index.

One international journal boasts that they are in:

Google Scholar, CrossRef, CiteFactor, ROAD, Academic Resource Index (Research Bib), Schlitt (Scientific Literature), SIS (Scientific Indexing Services), Research Gate, World Cat, Semantic Scholar.

Another Journal, in the realm of education indicates that: they are in all of the above BUT- they are also in DRJI (Directory of Research Journals Indexing) I mean that journal must be good correct?

Now, I am not sure how much time the reader has to review all of these above- but my time is limited, as is most researchers and scholars. 
Lastly, one fine journal indicates that it is now indexed with and included in Cabell's, Ulrich's EBSCO, Index Copernicus International, Gale and is also working and is "under the indexing process with ISI, ERIC, DOAJ, JSTOR, ECONLIT and SCOPUS.

It would seem that nowadays that every scholar has to have access to a librarian to assist with evaluating every journal that is available and ascertaining the Index and other relevant information about the journal (as well as how much it costs to review the paper and then publish the paper).

\section{Conclusion}

Publishing one's research, one's literature review or case study or either one's qualitative or quantitative research has become much more difficult and fraught with peril. This paper has reviewed some of the concerns confronting new scholars and researchers as they are confronted with increasingly complex challenges and issues.

\section{REFERENCES}

1. Teixeira da Silva JA, Shaughnessy MF. An Interview with Jaimie A. Teixeira da Silva: Insights into Improving the efficiency of the publication process. N Am J Psychol. 2017;19(2):325-38.

2. Beall J. The open-access movement is not really about open access. Triple C. 2013:11(2):589-97.

3. Beall J. Predatory journals: Ban predators from the scientific record. Nature. 2016;534(7607):326.

4. Beall J. What I learned from predatory publishers. Biochem Medi (Zagreb). 2017;27(2):273-78.

5. Teixeira da Silva JA, Tsigaris P. What Value Do Journal Whitelists and Blacklists Have in Academia? 2018; 44(6):781-92 . 